\title{
Sleeve resection of the left main bronchus for delayed extraction of a chicken bone
}

\author{
Alper Toker, MD, Serhan Tanju, MD, and Berker Ozkan, MD, Istanbul, Turkey
}

A 55-year-old woman who aspirated a chicken bone 4 years previously was admitted to the Istanbul Medical School with a history of recurrent pneumonia. She had several unsuccessful bronchoscopic attempts in different centers. Bronchoscopic examination demonstrated a granulation tissue that caused complete airway obstruction of the left main bronchus. Sleeve resection and reconstruction of the left main bronchus were performed supra-aortically. The aim of this report is to present the complication of retained organic foreign body and complicated procedures for correction of this complication.

\section{CLINICAL SUMMARY}

Organic foreign bodies in airways generally indicate an immediate bronchoscopy. A retained foreign body is sometimes the result. We describe a patient who underwent several unsuccessful attempts for extraction. We describe a major operation for the treatment of a retained organic foreign body.

A 55-year-old woman who aspirated a chicken bone 4 years ago had recurrent pneumonias within the last 12 months. She was admitted to the Istanbul Medical School after such an episode of pneumonia with the symptom of dyspnea. A computed tomography scan revealed obstruction of the left main bronchus at the carinal level (Figure 1). On physical examination, audible wheezing was present. Bronchoscopic examination before surgery demonstrated a granulation and fibrotic tissue that caused complete airway obstruction of the left main bronchus. Dilatation with a rigid bronchoscope was not successful and was considered dangerous. Thus, posterolateral thoracotomy was performed. Maneuvers to dissect the left main bronchus were performed after dissecting the left main pulmonary artery and dividing the ductus arteriosus. However, there were tight adhesions at the carinal level and it was impossible to perform an anastomosis under the aortic arch. The aortic arch was mobilized after ligating 2 more intercostal arteries. Via a distal bronchotomy, the bone was extracted and a segmental resection of the left main bronchus was performed.

\footnotetext{
From the Istanbul University, Istanbul Medical School, Department of Thoracic Surgery, Istanbul, Turkey.

Received for publication Dec 4, 2007; accepted for publication Feb 5, 2008

Address for reprints: Serhan Tanju, MD, Tasmektep sok, Cinarli Apt 34/5 34730,

Goztepe, Istanbul, Turkey (E-mail: drstanju@hotmail.com).

J Thorac Cardiovasc Surg 2009;137:768-9

$0022-5223 / \$ 36.00$

Copyright (c) 2009 by The American Association for Thoracic Surgery doi:10.1016/j.jtcvs.2008.02.057
}

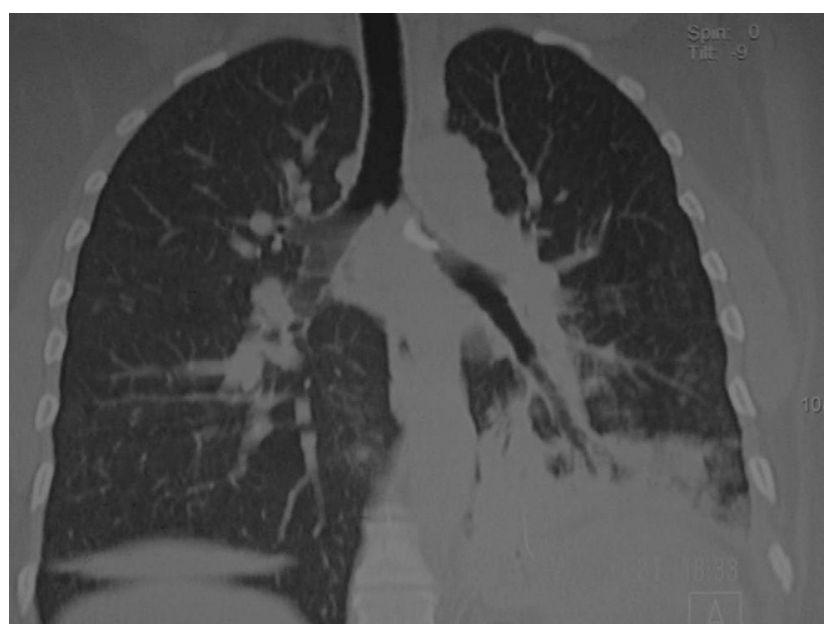

FIGURE 1. Reconstructive computed tomography scan of the patient 4 years after foreign body aspiration. Chicken bone can be seen.

A supra-aortic anatomosis was performed with PDS 40 (Ethicon, Johnson \& Johnson, Somerville, NJ) sutures with a continuous technique (Figure 2). She was discharged on postoperative day 6 without any complication. A computed tomography scan revealed a healthy anastomosis 3 months postoperatively.

\section{DISCUSSION}

Foreign body aspiration can cause a wide range of clinical outcomes, such as acute asphyxia and recurrent pulmonary infections, and can be a life-threatening emergency. ${ }^{1}$ Rigid bronchoscopy is indicated on appropriate history and suspicion to prevent delayed diagnosis. ${ }^{2}$ Chronic debilitating symptoms with recurrent infections might occur with delayed extraction, or the patient may remain asymptomatic. In adults, because the right and the mainstem bronchi diverge from the trachea with different angles, foreign bodies are more often found in the right system. In the series of 63 patients reported by Debeljak and colleagues, ${ }^{3} 66 \%$ of foreign bodies were found in the right endobronchial tree. In our patient, the foreign body was located in the left main bronchi.

In patients with delayed foreign body aspiration, local inflammation, edema, cellular infiltration, ulceration, and granulation tissue formation might ensue and cause difficulty in removal of the object. Organic foreign bodies and repeated rigid bronchoscopy attempts, such as in our case, 


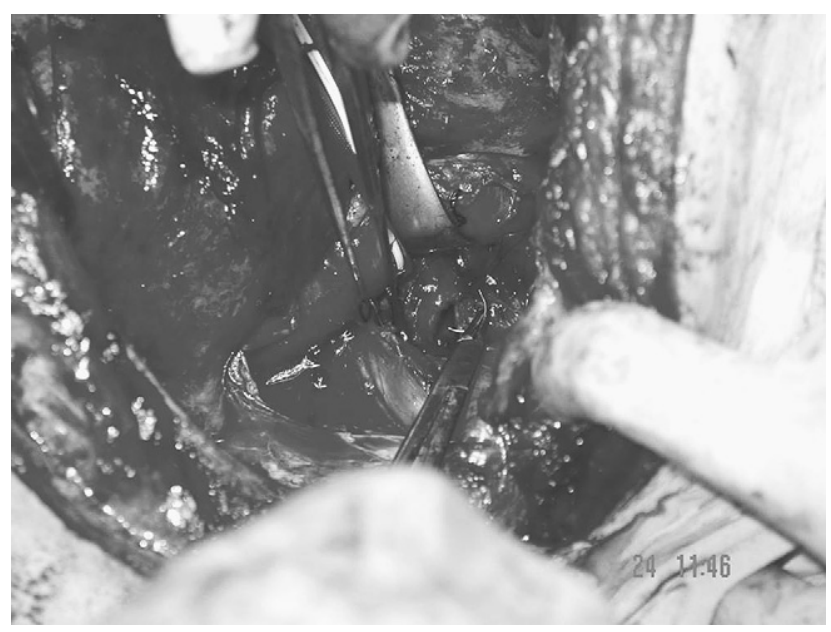

FIGURE 2. Anastomosis of the left main bronchus to tracheocarinal level above the aortic arch and in front of the esophagus.

induce inflammation and edema; therefore, serious endoluminal obstruction may occur. Recurrent suppurative pneumonia can occur due to obstruction. Our patient aspirated a chicken bone 4 years previously and underwent several rigid bronchoscopy attempts to extract the foreign body. She was admitted to the Istanbul Medical School after an episode of pneumonia and had dyspnea and audible wheezing because of near total airway obstruction diagnosed via bronchoscopy. Ibrahim Sersar and colleagues ${ }^{2}$ reported a series of 3300 patients, 3 of whom required bronchotomy because extraction of the inhaled foreign body failed. ${ }^{2}$ In another study, ${ }^{4} 164$ patients underwent bronchoscopy for foreign body aspiration, and $6 \%$ of patients required surgical extraction. Early bronchoscopy has high successful rates in the extraction of foreign bodies. Bronchotomy is usually enough to extract the foreign body, which was performed after early bronchoscopy. Because of the delay in extraction, our patient required an extended operation, a segmental main bronchial resection with supra-aortic anastomosis. After unsuccessful attempts, a bronchotomy would have been a less-invasive procedure for this patient. Thus, we advise an early operation for organic foreign bodies.

\section{CONCLUSIONS}

Early diagnosis of foreign body aspiration depends on high clinical suspicion, clinical signs, and radiologic findings. It is important to extract the foreign body via an early endoscopy or a surgical approach because retained organic foreign bodies may cause severe anatomic problems in the airways and require complicated surgical procedures.

\section{References}

1. Pinzoni F, Boniotti C, Molinaro SM, Baraldi A, Berlucchi M. Inhaled foreign bodies in pediatric patients: review of personal experience. Int J Pediatr Otorhinolaryngol. 2007;71:1897-903.

2. Ibrahim Sersar S, Hamza UA, AbdelHameed WA, AbulMaaty RA, Gowaeli NN Moussa SA, et al. Inhaled foreign bodies: management according to early or late presentation. Eur J Cardiothorac Surg. 2005;28:369-74.

3. Debeljak A, Sorli J, Music E, Kecelj P. Bronchoscopic removal of foreign bodies in adults: experience with 62 patients from 1974-1998. Eur Respir J. 1999;14:792-5.

4. Cataneo AJ, Cataneo DC, Ruiz Jr RL Management of tracheobronchial foreign body in children. Pediatr Surg Int. 2008;24:151-6; Epub 2007 Nov 6.

\title{
A successful neonatal repair of congenital aortic aneurysm with cleft sternum
}

\author{
Yasutaka Hirata, MD, ${ }^{a}$ Marc S. Arkovitz, MD, ${ }^{\mathrm{b}}$ Charles C. Marboe, MD,${ }^{\mathrm{c}}$ and Ralph S. Mosca, MD, ${ }^{\mathrm{a}}$ New York, NY
}

\footnotetext{
From the Divisions of Cardiothoracic Surgery, ${ }^{\mathrm{a}}$ Pediatric Surgery, ${ }^{\mathrm{b}}$ and Pathology, Department of Surgery, Columbia University College of Physicians and Surgeons, New York, NY.

Received for publication Dec 5, 2007; revisions received April 25, 2008; accepted for publication June 21, 2008.

Address for reprints: Yasutaka Hirata, MD, The Division of Pediatric Cardiac Surgery, Columbia University College of Physicians and Surgeons, New York, NY (E-mail: yh2240@columbia.edu).

J Thorac Cardiovasc Surg 2009;137:769-71

$0022-5223 / \$ 36.00$

Copyright (c) 2009 by The American Association for Thoracic Surgery

doi:10.1016/j.jtcvs.2008.06.037
}

Thoracic aortic aneurysm is rare in the pediatric age group; only a few cases have been described and are often associated with connective tissue disorders such as Marfan or Ehlers-Danlos syndrome ${ }^{1}$ or coarctation of the aorta. ${ }^{2}$ The association of aortic aneurysm with a sternal defect in infants or children has been previously reported on only 3 occasions. ${ }^{3-5}$ Although the long-term morbidity is unknown, 2 of the 3 patients had either progressive dilation ${ }^{4}$ or rupture ${ }^{5}$ of the aneurysm. We report a successful repair of congenital aortic aneurysm and cleft sternum in a neonate. 